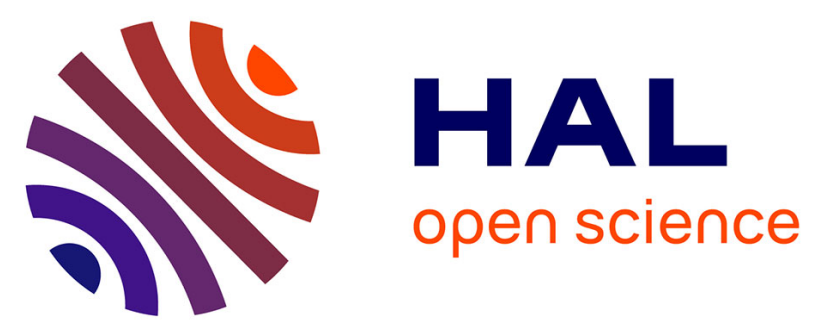

\title{
Field return on a Chinese-French double graduation of an International Master in Microelectronics on the Base of the Bologna Process
}

\author{
Olivier Bonnaud, Lotfi Senhadji, Lei Wei, Limin Luo, Hélène Frémont, \\ Huazhong Shu
}

\section{To cite this version:}

Olivier Bonnaud, Lotfi Senhadji, Lei Wei, Limin Luo, Hélène Frémont, et al.. Field return on a Chinese-French double graduation of an International Master in Microelectronics on the Base of the Bologna Process. 9th International Conference on Information Technology Based Higher Education and training - ITHET 2010, Apr 2010, Cappadocia, Greece. pp.324 - 327, 10.1109/ITHET.2010.5480087 . hal-00479107

\section{HAL Id: hal-00479107 https://hal.science/hal-00479107}

Submitted on 27 Jan 2013

HAL is a multi-disciplinary open access archive for the deposit and dissemination of scientific research documents, whether they are published or not. The documents may come from teaching and research institutions in France or abroad, or from public or private research centers.
L'archive ouverte pluridisciplinaire HAL, est destinée au dépôt et à la diffusion de documents scientifiques de niveau recherche, publiés ou non, émanant des établissements d'enseignement et de recherche français ou étrangers, des laboratoires publics ou privés. 


\section{Field return on a Chinese-French double graduation of an International Master in Electronics and Telecommunications on the Base of the Bologna Process}

\author{
Olivier BONNAUD \\ Responsible of the International Master of Electronics and \\ Telecommunications \\ (Microelectronics), \\ University of Rennes 1, Rennes, France \\ olivier.bonnaud@univ-rennes1.fr
}

\section{Lei WEI}

Responsible of the International Master of Electronics and Telecommunications (Microelectronics), Southeast University, Nanjing, China. lw@seu.edu.cn

\section{Hélène FREMONT}

IMS UMR 5218, University of Bordeaux

Talence, France.

helene.fremont@ims-bordeaux.fr

\author{
Lotfi SENHADJI \\ Responsible of the International Master of Electronics and \\ Telecommunications \\ (Signal \& Image Processing), \\ University of Rennes 1, Rennes, France \\ lotfi.sehnadji@univ-rennes1.fr
}

Limin LUO

Responsible of the International Master of Electronics and Telecommunications

(Signal \& Image Processing), Southeast University, Nanjing, China. luo.list@seu.edu.cn

\section{Huazhong SHU}

School of Computer Science and Engineering, Southeast University, Nanjing, China shu.list@seu.edu.cn

formations in Asia-Pacific region on the basis of the local studies. By this way, new students are registered in the field and potentially may supply the doctoral schools and increase the human power of the research laboratories not only in European countries but also in the hosting country. This approach gives also the opportunity to establish or improve the scientific exchanges between institutions and mainly at the level of their related research laboratories. Some interesting results that can be highlighted are the joint doctoral programs that allow common works, common scientific publications that also may lead to international joint laboratories.

This paper deals with the set-in of a new master degree in the field of electrical engineering and information processing, with two specialties: microelectronics and signal and image processing. It is a double diploma ("one plus one" diploma) between South-East University (SEU) located in Nanjing (China) and the University of Rennes 1 (UR1), Rennes (France), fully compatible with the Bologna process rules more especially in terms of ECTS (European Credit for Transfer System). The main advantage of this approach is to give the opportunity to the best Chinese students to obtain in parallel to their Chinese diploma, a master diploma that is recognized in all the European countries in the scheme of the bologna process

that is unfortunately more and more common in Europe, several French Institutions are trying to build remote 
[1], at least. In order to insure as high as possible quality for the syllabus, the program also includes other French institution professors that are already involved in the Rennes's master. For example, a specialist from the University of Bordeaux 1 in the field of reliability in microelectronics, a module item of the global syllabus of the double diploma, is participating to remote lectures.

\section{SET-UP OF THE PROJECT}

With the support of the Presidents of the two universities and thanks to a previous cooperation existing at the level of the research (French-Chinese Biomedical Information Research Center, an International Joint Laboratory of Southeast University, The University of Rennes 1 and the INSERM in the field of Biomedical Signal and Image Processing), the contacts were easily established with the academic partners. Only two general meetings of the concerned professors on both sides were necessary to build the bases of the common project in less than six months. Of course, the administrative part that followed was a little bit longer in order to validate the diploma by the academic institution instances. The previous existence on one side, in Rennes, of a master in Electronics and Telecommunications with two specialties, CTS (Components, Systems, Technology) in the field of microelectronics, and SISEA (Signal, Image, Embedded System, Automation), in the field of Signal and Image processing [2], and on the other side, in Nanjing, of masters in electrical engineering and in computer sciences - biomedical engineering, was a good opportunity, thanks to a strong overlapping of their syllabus, to build a joint program covering these two specialties [3].

To pass over the language difficulties, all the lectures are performed in English. The students are strongly selected with regard to their scientific level - all the students were at the first top positions in their respective bachelor classes - but also on their level in English language.

The curriculum was built on the basis of reciprocal powers to take maximum advantage of the expertise of each side. For this purpose, the credits are shared and taught by the two institutions and their local partners.

As the bachelor degree in China is four year long instead of three years in Europe (and thus in France), it is obvious that the students in some modules of the Master of Rennes already obtain some competences. That is the reason why some credits already obtained within Bachelor curricula are validated in the common master. In other words, similar lectures that were validated on China side are validated on French side at the level of the first year of the European master. Figure 1 gives a comparison between the two systems.

The links mentioned on the figure are used to give some equivalence and thus validation of ECTS (on the European side). The ultimate goal is to reach the same number of ECTS, which guarantees the quality and the official number of credits for a European Masters.

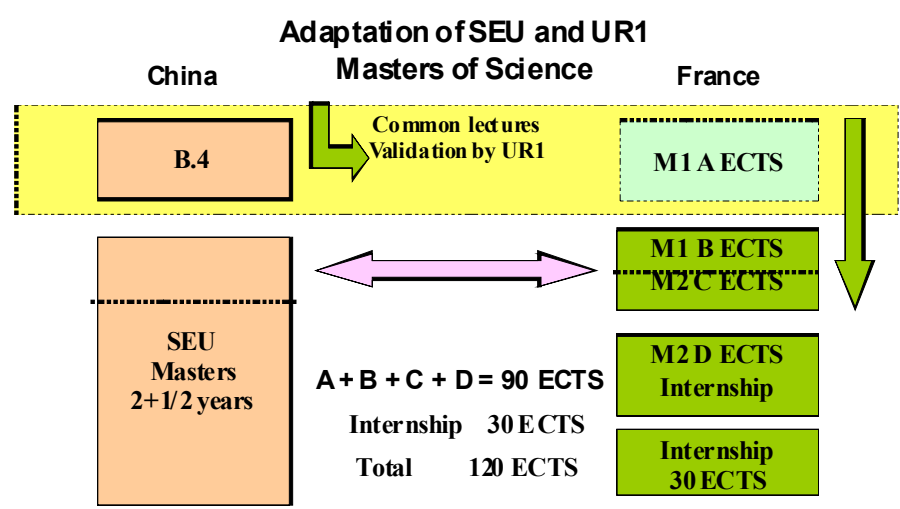

Figure 1. Figure 1. Comparison of both systems, Chinese and French ones. SouthEast University (SEU) has a four year long bachelor. University of Rennes 1 (UR1) a three year long license (or bachelor).

The only difference will come from the duration of the internship that is extended of six months to be compatible with the official Chinese program. Figure 2 shows the booklet that was established to promote this new international program.

The jury was built with parity representation of the two institutions. The jury must be organized in presence of at least six teachers involved in the modules. For University of Rennes 1 , the President of the jury must be a professor teaching within the University. The same is applied on SEU side.

\section{DEFINITION OF THE CONTENTS}

The contents were defined on the basis of both programs. On Rennes side, the master of the electronics and telecommunications contains two specialties: microelectronics (CTS) and signal and image processing (SISEA). On Nanjing side, the concerned masters are computer science and biomedical engineering and Electronic and Microsystems. The required background was verified on both sides. Some lectures are thus common at the first year of the master and constitute the common-core syllabus. The second year is fully devoted to the specialties. The lectures are shared between the partners and they proposed finally the two following paths with some details on the taught modules:

i. Microelectronics: Elements of Information Technologies - Development of Electronic Science - Embedded Systems - RF \& HF Electronics - Power Electronics Microtechnologies and Sensors - System Design - Mixt and HF circuit Design - Advanced Embedded systems Technologies of Devices - Test and Instrumentation Microtechnological sensors and Biosensors - MEMs Quality and Reliability

ii. Signal and Image Processing: Algorithm design Process control and vision - Advanced Signal Processing - Computer Vision - Software Design - Detection and Estimation - Kalman Markov Filtering - Optimization Classification and Fusion - Adaptive Filtering and Filter banks - Computer Science - Image Processing and Wavelets - Geometrical Modeling and Statistics Biomedical Engineering and Data mining - Pattern Recognition and Image Fusion - Image Sequence Analysis 
For these two specialties, each institution delivers more or less half of the lectures. Of course, the responsibility of the modules takes into account the dedicated field of competence, in order to reach the highest possible scientific level.

Concerning the financial aspect, a very important point, the two institutions contribute to the effective expenses in terms of staff cost and in terms of functioning expenses. The SEU makes an additional effort to fully contribute to the travel and accommodation of the teachers coming from France for an average period of one week along with they spent more or less twenty hours of lecture. This choice, that minimizes the travel expenses, has a consequence on the time-table and on the pedagogical methodology. A strong flow of information in the same field during few days is often a difficult exercise. However, it is also a good experience preparing the students to the life-long learning that can probably apply in their future carrier of engineer or doctor.

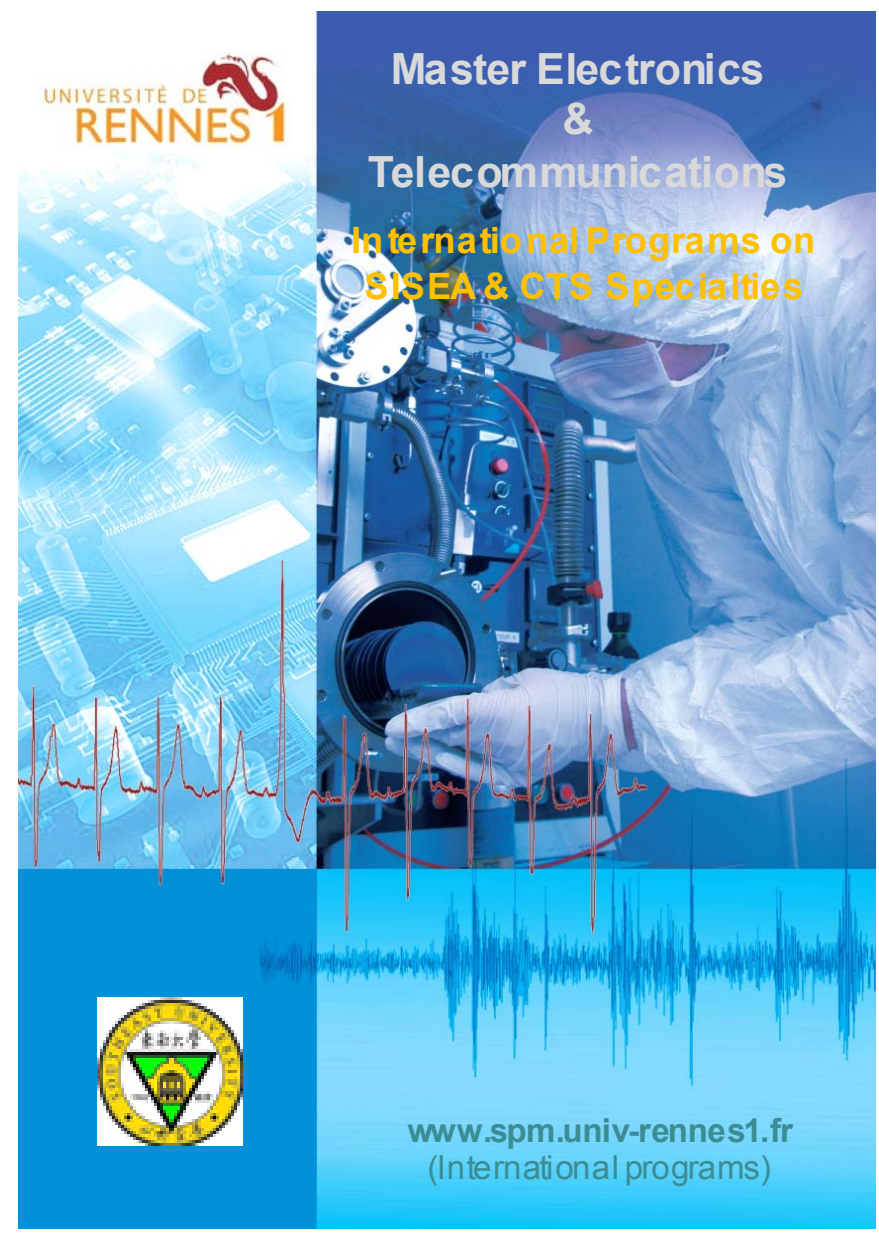

Figure 2. Figure 1. Figure 2. Booklet of presentation of the international program of the master built by SEU and UR1

\section{FIELD RETURN}

After more than one year of functioning, we may give some field return.

The first point is related to the adaptation of the pedagogy. The teachers have to spend their lectures in English that is not the mother tongue of the students as well. This means a more cautious approach but using simple and clear oral expressions, with slow flow, with a well built and well documented media support (slides and lecture notes), by defining the vocabulary, by controlling the symbols and notations (in agreement with the previous studies), and by establishing interaction and good contacts with the students. This is particularly easy as the students are not too much numerous, and also really willing and motivated.

The second point concerns the matching of both institutions by taking into account the different pedagogical methods. At the master levels, the French teachers of the concerned fields try to have more a scientific overview than demonstration and calculation, suggest less memory knowledge and more understanding and synthesis mind than the Chinese students had in average during their bachelor preparation; more especially, some lectures need a solid background in many domains, as well chemistry, mathematics as quantum physics, mechanics, thermodynamics, statistics, optics, computer automation, signal processing and electronics circuits and devices. This corresponds to a new approach related to a new audience that involves a different methodology of teaching included in a different way of progress, and overall, the adaptation of the students. The first hours of lecture constitute a reciprocal observatory, and a very rich experience. At this level and due to the strong interest and investment of the students, the results are rapidly positive and create a reciprocal confidence between students and teacher.

\section{FIRST PROMOTION AND RESULTS}

This master has started the 2008-2009 academic year and the first $1+1$ master degree diploma (two years) is almost delivered at the time of this proposal. The first promotion gathered 17 students, the second one that has started in September 2009, 35. Thus, the attractiveness of such a program is already proven and is presently very high.

In the second promotion, almost half of the students were major of their Bachelor classes (they are coming from many Chinese institutions) after the National contest for entering the master degrees of the SEU!

The jury of the first year of the master was held in November 2009. The first promotion results were particularly exceptional in term of quality and homogeneity. The students have over passed the barrier of language and were very well adapted to the new pedagogical approach.

All the students succeeded with a mark at least at level "good" that represents usually the first top-10 of a class in France. Of course, the entrance selection was hard, and only the excellent students were chosen. However, they constitute a "shop window" for the two Universities and a very nice experience for the teachers. A simple evaluation survey made by the students showed their strong interest of this new experience.

\section{ACKNOWLEDGMENT}

The authors are very indebted to President H. Yi of the SouthEast University and to President G. Cathelineau and to 
Past-President B. Fortin of the University of Rennes 1. The authors would like to thank the Vice-President $\mathrm{Y}$. $\mathrm{Pu}, \mathrm{B}$. Wang and JJ. Durand for their strong support and help for building and starting this new international master. Many other professors and staffs of the two universities have also contributed to set-up this specific joint degree; the authors would like to thank all of them.

\section{REFERENCES}

[1] The Bologna Declaration on the European space for higher education: an explanation, 1999 http://europa.eu.int/comm/education/policies/educ/bologna/bologna.pdf

[2] see http://www.univ-rennes1.fr

[3] see http://www.seu.edu.cn. 